NBER WORKING PAPER SERIES

\title{
AN ECONOMIST SELLS BAGELS: A CASE STUDY IN PROFIT MAXIMIZATION
}

\author{
Steven D. Levitt \\ Working Paper 12152 \\ http://www.nber.org/papers/w12152 \\ NATIONAL BUREAU OF ECONOMIC RESEARCH \\ 1050 Massachusetts Avenue \\ Cambridge, MA 02138 \\ March 2006
}

I would like to thank Gary Becker, Stephen Dubner, Paul Feldman, Jeremy Fox, Ali Hortacsu, Kevin Murphy, and Chad Syverson, and seminar participants at the University of Chicago and Wharton for helpful comments. Paul Feldman generously provided the data used in the paper. Andrew Francis and Marina Niessner provided outstanding research assistance. This research was supported by research grants from Sherman Shapiro and the National Science Foundation. The views expressed herein are those of the author(s) and do not necessarily reflect the views of the National Bureau of Economic Research.

C2006 by Steven D. Levitt. All rights reserved. Short sections of text, not to exceed two paragraphs, may be quoted without explicit permission provided that full credit, including $\odot$ notice, is given to the source. 
An Economist Sells Bagels: A Case Study in Profit Maximization

Steven D. Levitt

NBER Working Paper No. 12152

March 2006

JEL No. L2

\begin{abstract}
$\underline{\text { ABSTRACT }}$
Profit maximizing behavior on the part of firms is a fundamental, but rarely tested, assumption of economics. In this paper, I analyze the decisions made by an MIT trained economist running a company that delivers bagels and donuts. The simplicity and transparency of the business (e.g. marginal cost is easily observed) allow for direct tests of profit maximization in the quantities delivered each day and the prices that are charged. Using thirteen years of data representing more than 80,000 deliveries, I find that the company is extremely adept at determining how many bagels and donuts to deliver to a particular customer on a given day. In stark contrast, the company appears to price on the inelastic portion of the demand curve for the entire period, thereby foregoing a substantial share of available profits. I argue that these results generalize well beyond this particular case study: firms are likely to be close to the efficient frontier on dimensions for which there is frequent and informative feedback regarding profits, but absent that feedback, systematic deviations from profit maximization are more likely.
\end{abstract}

Steven D. Levitt

Department of Economics

University of Chicago

1126 East 59th Street

Chicago, IL 60637

and NBER

slevitt@uchicago.edu 
For the last twenty years, an economist with graduate training from MIT has made a business of delivering donuts and bagels to Washington, DC area businesses. Workers at these firms buy these goods on the honor system, depositing their payment in a lockbox that is picked up later the same day. The data generated by this business provide an unusual window onto the question of profit maximization. The assumption of profit maximizing behavior by firms is one of the most fundamental and widely applied in all of economics. Virtually all models of production start with profit maximization. The assumption of profit maximization is particularly critical to modern empirical industrial organization techniques which rely on indirect identification approaches to overcome the fact that important components of the inputs to a firm's decision (e.g. marginal cost) are not observable to the econometrician. ${ }^{1}$

In principle, testing for violations of profit maximization is straightforward. At least in the long run, no profit maximizing firm should set price below marginal cost, choose a price at which demand is inelastic, or stop production when marginal revenue exceeds marginal cost. Yet, direct attempts to empirically test the assumption of profit maximization are quite rare. One reason is that real-world firms are typically quite complex, producing multiple goods and using large numbers of inputs. As a consequence, detailed information on marginal cost is rarely available. Estimating the price elasticity of demand is also not a trivial task, although great progress has been made in this area in recent years (Ackerberg et al. 2005). A few prior analyses have attempted to overcome these difficulties. Genesove and Mullin (1998) analyzes the sugar industry

1 See, for instance, Rosse (1970), Pakes (1986), Bresnahan (1987), Bresnahan and Reiss (1991), Berry, Levinsohn, and Pakes (1995), and the dozens of papers that these seminal contributions have spawned. 
in the period 1890-1914, arguing that the production technology used by various refiners was fixed and known, which allows them to measure marginal costs accurately. Wolfram (1999) and Hortacsu and Puller (2005) both study the electricity industry, in which the short run marginal costs are almost exclusively driven by fuel costs.

In this paper, I analyze the extent to which the behavior of the bagel and donut delivery business described above makes profit maximizing choices. ${ }^{2}$ There are a number of reasons why this firm would a priori be a leading candidate to maximize profits. First, the service the firm provides is very simple. The firm has only one line of business. The marginal cost of delivering one more bagel or donut to an existing customer is simply the wholesale price of the good, a number which is easily observed by the company's owner. Second, the firm gets frequent and detailed signals of demand. Each day, for each customer, the owner chooses the quantity of bagels and donuts to deliver. Later that day he observes how many of the goods go uneaten, as well as the revenue collected. ${ }^{3}$ Third, the owner is well-trained in the principles of profit maximization. He is ABD in Economics from MIT (leaving MIT in 1962), has published research in Journal of Political Economy (Feldman 1971) and American Journal of Political Science (Feldman and Jondrow 1984), and spent more than twenty years working as a professional economist before starting this business. Fourth, the owner both makes the decisions and is the residual claimant on the profit flows; there is no principalagent problem at work.

\footnotetext{
${ }^{2}$ The analysis I undertake encompasses only a part of the firm's overall profit maximization. I do not examine whether the firm is cost minimizing in its choice of inputs, how it attracts new customers, or its decision about which products and services to supply.

${ }^{3}$ Because customers pay on the honor system, revenues are not simply the quantity eaten multiplied by the posted price.
} 
Analyzing 13 years of data representing more than 80,000 deliveries of bagels and donuts to clients, the findings concerning profit maximization are mixed. The company is extremely adept at choosing the optimal quantities to deliver on a daily basis at a given price. The fact that the firm gets quantities almost exactly right, combined with the fact that the profit function is flat near the optimum, implies that there is little scope for improving profits in this dimension. Although I show that a regression model can improve on the firm's choices, it improves the bottom line by just a fraction of a percent.

In stark contrast, however, the prices set by the firm, appear to be far from profit maximizing. The firm prices on the inelastic part of the demand curve over the entire period of study, i.e. price increases lead to an increase in both revenues and profits. My calculations suggest that mispricing lowers firm profits by perhaps 30 percent.

In light of the information available to the firm, the patterns observed are not particularly surprising. The firm receives daily feedback regarding each customer's demand for the goods at a given price, and given this information, incorporates it extremely efficiently. The daily activities of the firm, in contrast, yield little information that is useful in determining the optimal price. The firm perceives price changes as costly to make, thus they occur infrequently. Thus, one would expect that the firm would do a better job of choosing quantity conditional on price then identifying the optimal price.

The remainder of the paper is structured as follows. Section II describes the data set in greater detail. Section III derives the profit maximizing choices in a model that captures key aspects of the firm's particular decision problem. Section IV presents the results testing for the profit maximizing choice of quantities delivered holding price constant. Section V analyzes the choice of prices. Section VI concludes. 


\section{Section II: Background and data}

The company began operations in 1984. The nature of the business is straightforward. It purchases bagels, cream cheese, and donuts wholesale, which it delivers to local businesses in the morning. The food is left in a central area, along with a sign that states the prices, and a wooden lock-box in which customers leave their payments on the honor system. Later that day, a company employee returns to collect the money and any uneaten pastries. ${ }^{4}$ The company does not charge the offices to which it delivers for the service provided. Revenues accrue solely from payments for the bagels and donuts. ${ }^{5}$ The typical client firm receives a delivery once per week. In an average week in the sample, the company delivers more than 3,000 bagels and 1,500 donuts to roughly 125 different clients.

The founder of the company generously provided detailed records of the firm's operations. These data consist of the amount of bagels, cream cheese, and donuts delivered, the amount of money collected day, and the number of bagels and donuts that go uneaten. All of this information is reported separately for each client, each day. In addition, the data include both the posted prices that customers are charged, as well as the wholesale costs of the bagels, cream cheese, and donuts. ${ }^{6}$ These data cover the period January 1993 to December 2005. As noted earlier, the company began deliveries almost a decade earlier, but the early years of data are not in a machine readable format. ${ }^{7}$ The

\footnotetext{
${ }^{4}$ For more details of the daily operations, see Levitt and Dubner (2005).

${ }^{5}$ A small number of companies pay full price in advance for the company's services as a perk for company employees. These companies are excluded from the analysis of this paper.

${ }^{6}$ I also know something about the wages and other operating costs paid by the firm, but these are not used in the analysis.

${ }^{7}$ The data for 1993-1996 were also available only in hard copy, but were scanned or hand entered.
} 
data appear to be of very high quality, but required some cleaning, the details of which are described in the Data Appendix.

Table 1 presents summary statistics for the data set. The unit of observation is a delivery to a particular office on a specific day. ${ }^{8}$ The table presents means, overall standard deviations, and within-office standard deviations over time. Because virtually all of the analysis I do is concerned with decisions at a single point in time, prices used in the paper are in nominal dollars, except where otherwise noted. There are a total of 80,731 deliveries, with an average of approximately 30 bagels and 13 donuts per delivery. More than 90 percent of the bagels and donuts delivered are actually eaten.

The nominal price customers are charged for bagels changes three times over the course of the sample. Initially the nominal price for bagels was 60 cents. That price jumped to 75 cents in August 1993, 85 cents in August 1998, and \$1.00 in May 2003. The nominal price of donuts is 50 cents over almost the entire sample, increasing to 60 cents in March 2005. In real terms, the price of bagels in 2005 dollars varies between a low of roughly 80 cents at the beginning of the sample before the first price increase and a high of slightly more than a dollar after the last price change. The real price of bagels slowly falls from about 70 cents at the beginning of the sample to roughly 50 cents over the sample period due to inflation, before rising to 60 cents after the price change.

Because payments are made on the honor system, the firm's revenue is less than the posted price. On average, the payment rate (defined as actual revenue divided by expected revenue if the posted price were paid for each good consumed) is slightly below

\footnotetext{
${ }^{8}$ In cases where deliveries are made multiple floors of an office building housing employees of the same company, the firm treats these as separate deliveries and I follow that practice as well.
} 
90 percent in the data. Because the payments are collected in a single lock-box at each client, payments for donuts versus bagels cannot be separately identified.

The marginal cost of delivering one more bagel or donut to an existing customer is simply the wholesale cost. The wholesale cost of a bagel (including cream cheese) rises steadily over the period from 20 cents to 37 cents. The wholesale cost of a donut is near 20 cents for most of the sample, but is slightly higher in the late 1990's, peaking at 26 cents in 2000 . The wholesale cost per unit is constant over relevant quantity ranges at a given point in time.

Figure 1 presents monthly time-series data on the total number of bagels and donuts delivered. Donuts represent an increasing share of the product mix over time. At the beginning of the sample, bagels represented more than 80 percent of the sales in both units and revenues. By the end of the data, the number of bagels and donuts sold are nearly equal, although due to changes in the relative prices charged, bagels continued to account for 70 percent of revenues. A clear seasonal pattern emerges in the time-series, with December deliveries always low.

\section{Section III: Modeling the Firm's Decision Problem}

Conditional on the set of products offered and the offices to which the company delivers, the two basic choices the firm faces are the prices to charge and the quantity of bagels and donuts to deliver to a particular office on a given day. In modeling these choices, I will assume that price is taken as fixed in the short run, with the quantity delivered (which is akin to capacity) adjusted on a daily basis in response to anticipated 
fluctuations in demand. Given that there are only four price changes in the 13 years of my sample, this appears to be an accurate reflection of how the company operates. Defining notation, let $X_{B}$ and $X_{D}$ represent the quantity of bagels and donuts delivered respectively. Bagels are assumed to be homogeneous, as are donuts. This ignores the fact that consumer preferences may vary across different varieties of bagels (e.g. plain versus poppy seed) or donuts. $P_{B}$ and $P_{D}$ are the posted prices of the two goods to the consumers. Because the goods are sold on an honor system, the price a consumer pays need not equal the posted price. I define the parameter $\theta$ as the fraction of the posted price that the company actually receives from a sale taking into account shirking on the honor system. Throughout the analysis, I will assume that the marginal payment rate $\theta$ is identical for bagels and donuts, and that the marginal payment rate is equal to the average payment rate (i.e. the marginal consumer is as honest as the average consumer). ${ }^{9}$ I will also assume that at the posted price and marginal payment rate, the revenue from the sale of the good exceeds the marginal cost (denoted $C_{B}$ and $C_{D}$ respectively). The firm's marginal cost of increasing the quantity delivered to an existing customer is constant and equal to the wholesale price of the good delivered. The firm maximizes expected profits.

Demand for the goods is characterized as follows. Consider first the case where the firm delivers bagels and donuts in sufficient quantities that every consumer's demand for each of the products at a given price is satisfied. There will be a demand for each product, denoted $N_{b}$ and $N_{d}$ respectively for bagels and donuts. If instead the firm only

\footnotetext{
${ }^{9}$ The results in Levitt (2006) suggest that the marginal payment rate may be a bit below the average payment rate and that buyers of donuts pay a slightly smaller fraction of the posted price. If this is true, the empirical results that follow will slightly overstate the profitability of the marginal unit of product delivered, particularly for donuts.
} 
delivered one of the products, the implied price of the product that is not delivered is infinite. Thus, the demand for the product that is delivered will be greater when the other product is not available as long as bagels and donuts are substitutes. The quantity of bagels demanded at the fixed price when no donuts are available is denoted as $N_{b}^{\sim d}$ and the quantity of donuts consumed when no bagels are available is denoted as $N_{d}^{\sim b}$.

If demand for one of the goods at a particular office on a given day exceeds the quantity delivered of that good, I assume that the good in short supply is rationed randomly among the consumers demanding the good. ${ }^{10}$ This assumption implies that the firm is not able to price discriminate between those consumers who will substitute towards the other good in case of a shortfall of their preferred product and those who will not. Thus, the residual demand for bagels is given by $N_{b}+\left(N_{d}-X_{d}\right)\left(\frac{N_{b}^{\sim d}-N_{b}}{N_{d}}\right)$. A parallel expression holds for donuts. The term inside the first set of parentheses is the excess demand for donuts given prices and the number of donuts delivered. The expression in the second set of parentheses is the number of extra bagels sold when the number of donuts delivered falls by one. (The numerator of that expression is the increase in bagel demand going from the case where no donuts are supplied to the situation where all donut demand is satisfied; the denominator scales it in terms of donuts.)

\footnotetext{
${ }^{10}$ In practice, consumers may alter their behavior in ways that make this assumption unrealistic. If consumers who preferences run bagels, nothing, donuts gain more from consuming a bagel than those whose preferences are bagels, donuts, nothing (because the latter group may still get a donut even if no bagels remain), then the former set of consumers may be more likely to show up early to ensure they obtain a bagel, for instance.
} 
The degree of cannibalization between bagels of donuts, $\frac{N_{b}^{-d}-N_{b}}{N_{d}}$, appears repeatedly throughout the analysis. To simplify notation going forward, I will define $\lambda_{b d} \equiv \frac{N_{b}^{\sim d}-N_{b}}{N_{d}}$, and likewise, let $\lambda_{d b} \equiv \frac{N_{d}^{\sim b}-N_{d}}{N_{b}}$ represent the number of extra donuts demanded when one less bagel is delivered.

The decision problem when demand is known with certainty

I begin with the simplest case in which the firm knows with certainty $N_{b}, N_{d}, N_{b}^{\sim d}$, and $N_{d}^{\sim b}$ for a particular customer. ${ }^{11}$ The firm's optimal decision boils down to a choice of one of three possible strategies: (1) bring both bagels and donuts and exactly meet the demand for each good by supplying $N_{b}$ and $N_{d}$ respectively, (2) only bring bagels and deliver $N_{b}^{\sim d}$ of them, or (3) only bring $N_{d}^{\sim b}$ donuts. Because the firm is assumed unable to price discriminate between consumers who will substitute and those who will not, there is no middle ground in which the firm elects to deliver a small quantity of one good - the same tradeoff exists between bagels and donuts when going from supplying zero to one donuts or from $N_{d}-1$ to $N_{d}$ donuts. Thus, either it is optimal to fully satisfy the first choices of the consumers, or to bring none of one of the goods. Formally, the firm chooses to bring both bagels and donuts unless $\lambda_{b d}>\frac{\theta P_{D}-C_{D}}{\theta P_{B}-C_{B}}$, in which case bringing only bagels is optimal, or $\lambda_{d b}>\frac{\theta P_{B}-C_{B}}{\theta P_{D}-C_{D}}$, in which case delivering

\footnotetext{
${ }^{11}$ Because the firm faces constant marginal costs and there is unlikely to be demand spillovers across offices, the optimal quantity decision for each customer can be made without reference to the circumstances of other customers.
} 
only donuts is optimal. The terms on the left-hand side of these expressions reflect the degree of cannibalization across the two goods. The terms on the right-hand side are the ratios of the markups. When one good has a much higher markup and consumption between the two is highly substitutable, delivering none of the low markup good will be optimal. Each unit of the low markup good sold generates less profit than is lost because fewer of the high markup good are sold. Empirically, for the parameters I estimate from the available data, the degree of substitutability between bagels and donuts is well below the threshold that makes it more profitable to deliver only the high markup good (bagels). Delivering both bagels and donuts, as the firm does to most customers, appears to be the more profitable strategy.

\section{The decision problem when demand is uncertain}

When demand is not known with certainty, the choice of optimal quantities to deliver of each good becomes more difficult. Because the goods are substitutes the residual demand for each good is a function not only of demand shocks for that good, but also is indirectly affected by demand shocks for the other good and the quantity delivered of the other good, due to stock outs. To fully characterize the solution to the problem in terms of the optimal number of bagels and donuts to deliver would require knowledge of the joint distribution of demand shocks across the two goods.

I follow a different path, which is to limit my focus to the first order conditions which hold at the optimum, rather than trying to solve explicitly for quantities. These first order conditions are expressed in terms of the probability that the last bagel or donut delivered is eaten, rather than in terms of absolute numbers of the product eaten and 
delivered. This approach captures the important intuitions of the problem in a simple way, although it does have the drawback that it is not an explicit solution.

\section{Uncertain demand with only one product}

To begin, take the simple case in which there is only one product, say bagels. At the profit maximizing point, the marginal cost of providing a unit of bagel $\left(C_{B}\right)$ must exactly offset the expected marginal revenue it generates, which is given by $\theta P_{B} * \operatorname{Pr}\left(N_{b}^{\sim d}-X_{b} \geq 0\right)$. The expected marginal revenue is the incremental revenue when the bagel is sold, $\theta P_{B}$ (remember that the firm does not receive the full posted price, but rather, that price scaled by the average amount of shirking), multiplied by the probability that the last unit of bagel delivered is eaten. Expressed in terms of the firm's choice variable, which is the number of bagels to deliver $\left(X_{B}\right)$, the first order condition for profit maximization is

(1) $\operatorname{Pr}($ Last bagel eaten $)=\frac{C_{B}}{\theta P_{B}}$.

The greater the markup over the marginal cost, the lower is the equilibrium probability that the last unit of the good supplied will be purchased. Note that the earlier assumption that price is fixed is still being maintained.

\section{Uncertain demand with two products}

In the one product case, the consumer faces a choice between buying the product or not. With the introduction of a second good, when there is a shortfall of one good, some of the demand will transfer to the other good, as long as there is a sufficient supply 
of that second good to satisfy the incremental demand. For example, in the case where there is a stock out of bagels, but no stock out of donuts, bringing more bagels will increase the sale of bagels, but some of that increase will come at the cost of reduced sales of donuts. This substitution across goods leads to an additional term in the first order condition for profit-maximization relative to the one-good case:

$$
\operatorname{Pr}(\text { last bagel eaten })=\frac{C_{B}}{\theta P_{B}}+\lambda_{d b} \frac{P_{D}}{P_{B}} * \operatorname{Pr}(\text { last bagel eaten }, \text { last donut not eaten })
$$

where $\lambda_{d b}$ is the degree of substitution to donuts from bagels. The foregone revenue from donuts when the number of bagels increases is proportional to the degree of substitutability between the two products, the ratio of the two prices, and the probability that the substitution will take place. Only when there is an excess supply of donuts and a shortage of bagels will increasing the number of bagels reduce the consumption of donuts. If there are already excess bagels available, adding more bagels will not affect the consumption of bagels or donuts. If there is a shortage of donuts, then a marginal reduction in donut demand due to increased supply of bagels will nonetheless leave no donut uneaten.

Comparing a situation in which only bagels are delivered (equation 1) to when both products are offered (equation 2), the equilibrium probability that the last bagel will be eaten is (weakly) higher when both goods are delivered. This implies a reduction in the number of bagels delivered when both goods are offered. This is true not only because of demand for bagels falls when donuts are offered, but also because increases in bagel sales leads to foregone revenue associated with cannibalizing donut sales on the 
margin. The only cases in which the probability the last bagel eaten is the same across the two situations is when there is no substitution between the products, or when there are never simultaneously a shortage of bagels and an excess supply of donuts. ${ }^{12}$

The corresponding first order condition for donuts is identical to that of bagels, except that the roles of bagels and donuts have been reversed:

$$
\operatorname{Pr}(\text { last donut eaten })=\frac{C_{D}}{\theta P_{D}}+\lambda_{b d} \frac{P_{B}}{P_{D}} * \operatorname{Pr}(\text { last donut eaten, last bagel not eaten }) .
$$

Empirically, bagels are the more expensive good and carry a larger markup. Comparing equations (2) and (3), the term before the addition sign pushes towards bagels stocking out less frequently than donuts. In the term after the addition sign, both the higher price of bagels, and the probability term reinforce the tendency for donuts to stock out. For reasonable values of the rate of substitution from bagels to donuts and vice-versa, therefore, the likelihood that donuts stock out will exceed that of bagels stocking out.

\section{Setting Optimal Prices}

The firm's price decision is standard: it wants to price such that marginal cost equals marginal revenue, following the usual inverse elasticity rule of choosing markups. To the extent that the two goods are substitutes or complements in demand, the pricing decision should also take into account spillovers across the two goods.

12 In the case of perfectly correlated demand shocks for bagels and donuts, for instance, it can be shown that donuts will always stock out before bagels (which have a higher markup). 


\section{Section IV: Testing for Profit Maximization in the Choice of Quantities}

Detailed data, combined with the straightforward nature of this company's business, provide an unusually direct opportunity to test for profit maximizing behavior on the part of the firm along two important dimensions of decision making: the choice of quantity and the choice of price. In this section I explore the choice of quantity to deliver.

The quantity decision when only one product is delivered

A subset of the customers to which the company delivers receive no donuts, only bagels. When only a single product is delivered, equation (1) captures the first-order conditions governing the optimal quantity to deliver conditional on a particular price. The determinants of the optimal quantity choice are the posted price of a bagel, the degree of underpayment on the honor system, the marginal cost, and the observed probability that all the bagels delivered are eaten. All of these factors are either known, or can be readily computed from the available data.

Table 2 analyzes the degree to which the firm's actions, on average over the course of a year, correspond to the prediction in equation (1). Each row of the table corresponds to a different year's data. The first four columns report the means of the four factors that enter into the first-order condition. Based on those data, columns 5-7 present the estimated profit generated from the penultimate bagel delivered, the last bagel delivered, and the predicted profit had one extra bagel been brought. ${ }^{13}$ If the firm is

\footnotetext{
${ }^{13}$ For a hypothetical increase in the number of bagels delivered from $N$ to $N+1$, assumptions are necessary since in the data I only observe whether $N$ bagels were eaten, but what is needed for this estimate is the probability that the $N+l$ bagel will be eaten. One way to approximate that probability is to compute the likelihood that the $N$ th bagel will be eaten, conditional on bagel $N-1$ being eaten, and to multiply that number by the probability that the $N$ th bagel is eaten. These probabilities are observed in the data, and among customers receiving only bagels, the likelihood that the $N$ th bagel is consumed given that the $N-1$ bagel is eaten is roughly 73 percent over the course of the sample, with a high of 75.8 percent in 1998 and a
} 
optimizing with respect to quantity delivered, the profit on the last bagel should be close to zero. By extension of that same logic, there should be positive profit associated with the next-to-last bagel, and losses associated with bringing one extra bagel. The results reported in Table 2 demonstrate that the firm's quantity choices correspond closely with the predictions of the model. Averaged over the whole sample, the expected profit on the last bagel delivered is 1.1 cents. ${ }^{14}$ Given marginal costs, prices, and the payment rate, the probability that all bagels are eaten that sets the profit of the last bagel to zero is .345 . The actual value observed in the data is .36 . Across years, the estimated profit on the last bagel delivered ranges from -5.2 cents to 6.4 cents.

Comparing the expected profit on the last bagel delivered to that of the penultimate and $N+1$ bagel provides a further measure of the firm's choice of quantity. Columns 5 and 7 of Table 2 present estimates of the expected profit associated with the $N-1$ bagel and the $N+1$ bagel. In column 5, the next-to-last bagel yields positive profits in all years, averaging between 10 and 11 cents over the entire sample. Thus, although there are a few years (especially in recent times) in which the last bagel delivered has a negative impact on profits, but there are no years in which the company would want to reduce average delivery size by more than one bagel (off of a baseline of roughly 30 bagels). Because there are relatively few customers who receive only bagels and the loss on the last bagel is small, these deviations from the optimal quantity have a minimal impact on the bottom line. Had the company lowered bagel deliveries by one to all

low of 65.6 percent in 2003. Those numbers are likely to be upper bounds on the likelihood that the $N+1$ donut is eaten given that donut $N$ is eaten. By using this overly optimistic number in my hypothetical calculations, I overstate the true profitability of increasing bagel quantities, making it easier to reject that the firm actually took the correct action on average in a year.

${ }^{14}$ The average revenue from a bagel in the sample, taking into account a payment rate less than 1 , is 64.1 cents. The marginal cost of a bagel, averaged over the sample, is 24.4 cents. So if the last bagel delivered were eaten with certainty, the marginal profit on that bagel would be 39.7 cents. If the last bagel delivered was never eaten the profit would be -24.4 cents 
clients in the years of the sample in which the last bagel delivered returned negative profits, the total increase in profit would be less than $\$ 200$ combined.

The hypothetical profit associated with delivering one extra bagel, shown in column 7, is consistently negative, producing a loss of 6 cents on average. There are no years in which the firm could have increased profits through an across the board increase of one bagel per delivery. The firm appears to do an extremely good job of choosing the quantity of bagels to deliver when that is the only product delivered.

The quantity decision when both bagels and donuts are delivered

The optimal quantity decision becomes more difficult when two products are delivered rather than one. Now, the probability that each of the goods stocks out, and the degree of cannibalization across the two goods become relevant. The stock-out rates are readily observed in the data. The degree of cannibalization across the two goods is not directly observable and must be estimated.

The ideal setting for estimating the substitution from donuts to bagels would be a randomized experiment in which the researcher systematically varies the number of donuts delivered, and then measures the change in consumption of both donuts and bagels. Likewise, one would want to induce random variation in the number of bagels delivered to identify the extent of cannibalization of donuts by bagels.

Unfortunately, this sort of randomization is not present in the data. The observed fluctuations in quantities delivered are clearly not exogenous. The company increases the number of bagels delivered when anticipated demand for bagels is high. To the extent that demand shocks for the two goods are positively correlated, demand for donuts will 
generally be higher when there is a large delivery of bagels than when the delivery is small. In practice, this will bias towards zero estimates of the cannibalization for these two goods based on observed variation in the data. ${ }^{15}$

As a crude proxy for the degree of cannibalization, I compare changes in the number of bagels and donuts consumed from one delivery to the next at a client for those cases where the quantity delivered of one good remains constant, but the quantity of the other good does not. ${ }^{16}$ I measure cannibalization of bagels by donuts as follows:

$$
\lambda_{b d}=\frac{\Delta(\text { Bagels_eaten })}{\Delta(\text { Donuts_eaten })} \mid \Delta X_{b}=0, \Delta X_{d} \neq 0
$$

where $\Delta$ reflects the change from one week to the next at a given customer. If, in response to six extra donuts being delivered, four more donuts and one fewer bagels are eaten, I would estimate a cannibalization effect on bagels by donuts of -.25 . The formula for cannibalization of donuts by bagels is identical, except with the values for bagels and donuts reversed in the equation.

Focusing on cases where the quantity delivered of one good remains constant has two benefits. First, in the case of stock outs of that good, the truncation point remains the same in both weeks, facilitating comparisons of the quantity demanded. Second, the fact that the quantity delivered of one good did not change suggests that the firm did not anticipate a large fluctuation in demand relative to the previous week (although if they deliver more of the other good it does suggest that they are relatively optimistic).

\footnotetext{
${ }^{15}$ Alternatively, increases in quantities of one good may be a response to changes in tastes at the customer, in which case the estimate of cannibalization I obtain would be biased upward.

${ }^{16}$ One institutional factor that aids in this estimation is that the firm almost always delivers donuts in multiples of six. Because of the lumpiness of the delivery quantity, small changes in perceived demand may lead to discrete jumps in donuts delivered, as implied by the standard sS model, somewhat mitigating the issues raised by endogeneity of the delivery size. For bagels, however, this lumpiness is not present.
} 
The results on cannibalization across products are presented in Table 3. The first column shows the changes in bagels and donuts consumed in cases in which there is no change from the prior week in the number of bagels and donuts delivered: the number of bagels eaten falls by .15 and the number of donuts eaten is reduced by .06 . These changes will serve as the counterfactual as to what would be expected had the quantities delivered not changed. Columns 2 and 3 present results when the number of donuts delivered changes and bagels delivered remains constant. Column 2 reflects cases where donuts delivered increase; column 2 has decreases in delivered donuts. In those instances when donut deliveries rise, the increase in the number of donuts delivered is 4.32 , with 3.25 of those extra donuts eaten. Bagel consumption falls by .63. Relative to the counterfactual in column 1, an extra 3.32 donuts are eaten, and bagels consumed fall by .47. This implies that each extra donut eaten cannibalizes .141 bagel sales. In column 3, the number of donuts delivered declines, leading to approximately two fewer donuts eaten and an extra .13 bagels consumed. Compared to the counterfactual in column 1, donuts consumed fall by 1.97 and bagels eaten rise by .285 , for an implied cannibalization rate of roughly.145, nearly identical to the parallel figure for Column 2 . Columns 5 and 6 show the results when the number of bagels varies, with donut quantities held constant. When more bagels are delivered, an extra 1.07 bagels are eaten, and .28 fewer donuts. Relative to the column 1 counterfactual, bagels consumed rise by 1.22 and a .21 reduction in donuts, implying a cannibalization rate of .174 . When fewer bagels are delivered, bagels eaten fall by .725 , with an increase of .023 donuts. Compared to the counterfactual, this is a decline of .57 bagels and a .087 rise in donuts, 
for a cannibalization rate of .153 - once again close to the parallel value obtained in column 4.

Based on these cannibalization results, I proceed under the assumption that each extra donut eaten lowers bagels eaten by .144 , and that the cannibalization rate in the other direction is .163. Within plausible ranges, the results are not particularly sensitive to the choice of this parameter.

Table 4 reports the results on the estimated profitability of the last bagel delivered for customers who receive both bagels and donuts using equation (2). For purposes of comparison, I also report the implied profitability of the $N-1$ and $N+1$ bagel delivered, based on the same assumptions used in Table 2. As was true for clients who received only bagels, the firm does an outstanding job of choosing the quantity of bagels for customers who receive both products. On average across the entire sample, the firm earns less than one penny from the last bagel delivered. In four of the thirteen years, the last bagel delivered had a negative profit expectation, although in even the worst year the loss was only two cents. There are no years in which the company could have improved profits by lowering bagel deliveries by more than one per customer (i.e. the profits of the next to last bagel is always positive) or by increasing bagel deliveries across the board (i.e. the expected profit of the $N+l$ bagel is always negative).

Because the markup on bagels is greater than that of donuts, bagel stock-outs occur less frequently than donut stock-outs. As a consequence, it is relatively rare that all bagels are consumed, but donuts remain uneaten; this occurs between 5 and 16 percent of the time depending on the year. The infrequency of this circumstance coupled with the relatively low profit margin on donuts means that cannibalization considerations are of 
minor importance in the choice of bagel quantity. Referring back to equation (2), the presence of donuts reduces the optimal probability that the last bagel should be eaten by less than one percentage point on average.

The firm exhibits substantial skill in altering its behavior over time to achieve the profit maximizing delivery quantities. For instance, comparing 1996 and 2001, in both years the firm earned a small profit on the last bagel delivered. In 1996, however, the probability the last bagel is eaten is 35.3 percent, versus almost 45 percent in 2001 . Because the ratio of price to marginal cost is higher in 1996, the optimal probability that the last bagel eaten is lower, partially offset by the fact that in 2001 it is more frequently the case that there uneaten donuts available to absorb unsatisfied demand when bagels stock out.

Table 5 is identical to Table 4, except that the values reported represent the profit associated with the last donut delivered instead of the last bagel. Early in the sample, the firm does slightly worse in optimizing donut quantities than it does for bagels, but otherwise chooses the number of donuts extremely well. In the first three years of the data, the firm delivers too few donuts, i.e. the expected profit from adding one donut to each delivery is positive. There are three years later in the period where the last bagel delivered yields negative returns, implying that the firm would increase profit by reducing the quantity delivered. The foregone profits of these slight deviations from the optimal choice of quantity, however, are trivial: less than $\$ 300$ total across the whole sample.

Cannibalization is a much more important concern for donuts than bagels for two reasons. First, it is much more likely that there are excess bagels when all donuts are 
eaten then vice versa. Second, there is a larger markup on bagels than donuts, so a customer who substitutes a donut for a bagel is costly to the firm. Substituting the values observed in the data, cannibalization concerns raise the optimal probability of having the last donut eaten by 3 percentage points on average in the sample off of a baseline of a little more than 60 percent.

The estimates in Tables 4 and 5 average over all deliveries in a year. It is possible that the firm does well on average, but systematically delivers too much product to some clients and too little to others. To investigate this possibility, I estimate probit regressions in which the dependent variable is equal to one if all bagels are eaten on a particular delivery and zero otherwise. Explanatory variables include the number of bagels delivered this time as well as in the last two deliveries to this customer, the number of uneaten bagels in each of the last two deliveries, and indicator variables for stock-outs of bagels in the last two deliveries. Also included are the parallel variables for donut deliveries, as well as year, month, and day of the week indicators. All of the variables in the regression are observable to the company at the time the quantity decision is made. Using data from the preceding two calendar years, I generate out-of-sample predictions regarding the likelihood of a stock-out of bagels on each delivery. ${ }^{17}$ By basing my predictions only on the outcome of prior years of data, I ensure that only information available to the firm when making their quantity choice underlies my estimates. I then rank-order observations within a year with respect to the predicted likelihood of a stockout. I also carry out a parallel exercise for donut deliveries including the exact same set of explanatory variables.

\footnotetext{
${ }^{17}$ Because I require two years of earlier data to carry out this exercise, I do not make predictions for the first two years of the sample.
} 
A summary of the results is presented in Table 6 . The columns of the table correspond to my estimate of the likelihood of a stock-out. Column 1 represents the 10 percent of cases with my highest predicted likelihood of a stock-out. Column 2 reflects the half of the observations most likely to stock-out. Columns 3 and 4 are the bottom half and bottom 10 percent of predicted stock-outs respectively. The rows of the table report what actually happened in terms of leftovers for deliveries in each of these categories. The top panel presents results for bagels, the second panel corresponds to donuts.

The results in Table 6 demonstrate that the regression model has some power to predict delivery outcomes. Comparing columns (1) and (4) in the top panel of the table, in the 10 percent of cases where the model predicts a bagel stock-out is most likely, a stock-out occurs 52.7 percent of the time, compared to only 25.6 percent when the model deems a stock-out to be least likely. The fact that this probit model is able to generate systematic out-of-sample predictions means that the firm is not optimally incorporating all of the available information into its delivery decisions and could improve its performance using this information. ${ }^{18}$ The table also reports the expected profits from the delivery of the $N-1, N$, and $N+1$ bagel or donut delivered within each of the subsets identified by the regressions. For the 10 percent of observations where the probit model predicts the greatest likelihood of a bagel stock-out, it would have been profitable to deliver one more bagel. For the 50 percent of deliveries with the lowest stock-out probabilities, lowering the quantity delivered by one would have increased profits. Thus,

\footnotetext{
${ }^{18}$ Note that this model takes as an input the firm's choice of quantity to deliver, so the way that the firm would utilize the model would be to come up with quantity choices using their current approach, and then adjust quantities on the margin using the model. As a testimony to the skill of the firm in choosing quantities, I have been unable to build a model using only previous delivery outcomes that outperforms the firm's choices, in part because the firm has information about demand (e.g. special requests for large deliveries) that I do not observe.
} 
the regression model adds only trivially to what the firm already does. The increment to profits that would have been associated with incorporating the probit predictions into what the firm already was doing is less than $\$ 2,000$ combined over the entire sample.

The probit model identifies slightly greater deviations for donuts, as shown in the bottom panel of Table $6 .{ }^{19}$ Profits could have been increased by delivering one more donut to half of the customers and one less to the other half. For the top and bottom 10 percent of the sample, the firm would want to adjust the quantity delivered by at least two in the suggested direction. The contribution to profits of implementing the model's predictions with respect to donut quantities is approximately $\$ 1,500$ total over the sample.

\section{Section V: Testing for Profit Maximization in the Choice of Prices}

In contrast to quantities supplied, which vary for each customer on a delivery-bydelivery basis, there is little price variation. Over the course of thirteen years, nominal prices are changed on only four occasions, as noted earlier. Bagel prices are increased from 60 to 75 cents on August 31, 1993, from 75 to 85 cents on August 4, 1998, and from 85 cents to one dollar on March 5, of 2003. The price of donuts is at 50 cents until March 28,2005 , after which it rises to 60 cents. $^{20}$

\footnotetext{
${ }^{19}$ In defense of the firm's quantity choices, it is worth remembering that the firm delivers in increments of six donuts, whereas this analysis assumes that the firm can costlessly vary the quantity delivered by any discrete number of units.

20 According to the founder of the firm, the price increases were related to changes in costs and the perception that the prices they were charging were lower than competitors, such as Dunkin Donuts. The primary reason for infrequent price changes, according to the firm was fear that it would generate resentment among customers and adversely affect the willingness of customers to comply with the honor system. A second consideration was menu costs - the prices were attached to the boxes in which the money was collected in a way that made changing the listed prices time consuming. Experimenting with price changes is something he never seriously considered.
} 
Table 7 presents a simple comparison of the raw data (on a per delivery basis) from the three deliveries that immediately precede and follow each of the price changes for the set of customers for whom there are at least three deliveries in the month before and the month after the price change. Columns 1 and 2 correspond to numbers before and after the 1993 bagel price change. Before the price increase, an average of 51.4 bagels are delivered, of which 48.2 are eaten. After the price change, the number of bagels delivered falls to 49.3 , with 44.3 consumed. The number of donuts delivered and eaten, surprisingly, also falls slightly. Given the earlier cannibalization results, one would expect consumers to substitute from bagels to donuts in response to the price increase, but that is not observed. The data are instead consistent with a story in which the price increase leads to ill-will among customers. Also consistent with this hypothesis is that the payment rate falls from .914 to .888 with the price increase -- a pattern repeated with the later price increases.

After the price rises in August 1993, the firm's revenues increase, implying that (at least with respect to demand over a one month horizon) the firm was operating on the inelastic portion of the demand curve. This cannot be profit maximizing, and indeed profits are roughly 17 percent higher in the month after the price change than they were in the prior month. Under the assumption of a linear demand curve with a slope implied by the change in quantity associated with this price increase, I estimate the optimal bagel price to be $\$ 1.32$ at that time - well above the actual price, even after the price increase. ${ }^{21}$ If that linear demand curve is indeed accurate, then the firm's profit at the optimal price

\footnotetext{
${ }^{21}$ This estimate ignores any substitution from bagels to donuts when the price of bagels rises. If consumers switch to donuts, then the optimal price of bagels would be even higher, because some fraction of the lost bagel sales will be recouped by increased donut sales. Empirically, however, there is no evidence from any of the four price changes that raising the price of one good materially increases the quantity consumed of the other good.
} 
is roughly $\$ 28$ per delivery, or approximately 50 percent greater than the profits achieved before the price change. ${ }^{22}$

The remaining columns of Table 7 report the results from the other three price changes observed in the data. In every case, after the price increase, both the quantity delivered and eaten of that good falls and the payment rate declines. ${ }^{23}$ These declines, however, are not sufficient to offset the increased revenue due to the higher price. Thus, it appears that prior to each of the price increases, the company was pricing on the inelastic part of the demand curve. Profit rises between 4 and 10 percent over a onemonth horizon in response to these latter three price changes. The optimal price of a bagel, based on the assumption of a linear demand curve, is \$1.37 in 1998 and $\$ 1.71$ in $2003 .{ }^{24}$ The optimal price of a donut in 2005 is estimated to be $\$ 1.19$. These estimates do not appear unreasonable. On a recent visit to Dunkin Donuts, a bagel and cream sold for $\$ 1.79$ and a donut cost 69 cents. Optimal profits on bagels are estimated to be $40-60$ percent higher than the profits earned before the 1998 and 2003 price changes. Optimal profits from donuts are estimated to be twice as large as profits at the price charged prior to the 2005 donut price increase.

\footnotetext{
${ }^{22}$ The estimated number of bagels consumed at a price of $\$ 1.32$ is 29.29 . In my optimal profit calculation, I assume that the firm will have the same number of uneaten bagels at the optimal price, that the payment rate for bagels will fall to .85 , and that the profit generated by donuts will be unchanged.

${ }^{23}$ The quantities of the other good change only slightly in response to the price increase, declining in all instances.

${ }_{24}$ The firm's owner, in response to an earlier draft of this paper, argued that the assumption of linear demand is likely to overstate the optimal price. In his words, "The product we offer is not simply bagels and doughnuts. I think of it as a party. Remember, we deliver to most places only once a week and there is a "critical mass" issue. When I was working at CAN [where he worked before starting the bagel business], people would await my arrival on Friday morning and stand around chatting with each other while they were eating or waiting to get to the table. If we let the price get closer to that of our competition, the whole party aspect of the business - a bunch of people waiting for our arrival - would be lost." This logic is similar in spirit, though not precisely the same, as Becker (1991).
} 
Given these figures, a conservative estimate of the average loss in profits over the course of the sample due to mispricing is $30 \%$ of realized profits, or roughly $\$ 25,000$ annually. The losses due to improper pricing are two orders of magnitude greater than those associated with divergence of actual quantity delivered from the optimum.

One important caveat regarding the apparent mispricing of the goods is that, although price changes are associated with immediate increases in profits, demand may be more elastic in the long run than the short run. In that case, raising prices may have adverse consequences for profits down the road. To explore this possibility, I examine the pattern of profits in the two months preceding the price change and up to six months after the price change. In particular, I estimate time series regressions of the form

$$
\operatorname{Pr} \text { ofit }_{t}=\alpha+\sum_{m=1}^{6} \beta_{m} \text { PriceChange }_{t+m}+\sum_{m=1}^{6} \theta_{m} \text { PriceChange }_{t-m}+\Gamma X_{t}+\varepsilon_{t}
$$

where $t$ indexes time and $m$ corresponds to the number of months preceding or following a price change. The data are aggregated across all deliveries in a given day to generate one total profit number for each day. Indicators for the calendar year, the month, and the day of the week are included in the specification.

Table 8 reports the results of the estimation for specifications that consider various time windows before and after the price change. Column 1 presents results for a one-month window on either side of the price change. Relative to other days in that calendar year, profits are roughly $\$ 20$ (standard error of 16) a day lower in the month before the price change and $\$ 45$ higher in the month after (standard error of 15), for an increase of profits of $\$ 65$ a day, which is highly statistically significant. In column 2 , estimates are presented for the three months before and after a price change. The months leading up to the price change all carry negative but insignificant coefficients. The 
coefficients on the months after the price change are positive and significant with values between 53 and 60. There is no evidence that the increment to profits associated with the price change decays over this time period. When looking at the six months before and after the price change, the point estimates on the period four to six months after the price change, while still positive, are smaller in magnitude than those in the first three months. Using the estimates from the last column, daily profits are roughly $\$ 57$ higher after the price change, implying an increase in profits over the six month period of more than $\$ 6,000$, a magnitude slightly larger than implied by the raw data in Table $7 .{ }^{25}$

\section{Section VI: Conclusion}

Profit maximization is one of the most fundamental assumptions in economics, yet is rarely directly testable because of data limitations and the complexity of most firms. This paper provides a case study of the decision making of a firm whose activities and administrative data records lend itself quite naturally to an analysis of the choices it makes regarding the choice of prices and quantities to deliver conditional on these prices. In addition, the primary decision maker in the firm is an MIT trained economist. An analysis of the data suggests that the firm does an exceptionally good job of making the daily decision regarding the quantities to deliver to customers. In stark contrast, the evidence suggests that the firm has charged prices well below the optimal level for more than a decade, even to the point of pricing on the inelastic portion of the demand curve. I conservatively estimate that the firm sacrificed 30 percent of its potential profit through mispricing.

\footnotetext{
${ }^{25}$ There are no statistically significant differences between the rate at which customers appear or disappear from the sample before and after price increases.
} 
Although the findings of this paper apply directly only to the firm in question, there are reasons to believe that the results obtained here may be more broadly generalizable. It is not by chance that the firm does well in choosing what quantity to deliver. The problem is an intrinsically easy one in the sense that there is a direct mechanism linking the firms actions to the observed outcomes. By observing daily feedback about sales relative to product delivered, the firm is able to draw on an enormous volume of data in making the quantity decision. Any mistakes on the quantity dimension are quickly revealed and corrected. For firms more generally, the aspects of production which share these characteristics (such as inventory management and quality control) are well-studied, with substantial resources devoted by firms to optimizing these choices (e.g. Evans and Lindsay 1998, Silver et al. 1998).

In contrast, the firm rarely changes prices - only four times in the entire 13 year period - and thus gets little feedback regarding the right price. Without feedback, the firm has no direct mechanism for learning whether it is pricing correctly. This pattern of real-time adjustments in production rates coupled with much less frequent changes in prices appears to be a common practice among firms (Cecchetti 1986, Kashyap 1995, Bils and Klenow 2004,). Even with feedback, to the extent that price changes are an endogenous response to shifting demand conditions, the data generated will not directly inform optimal pricing decisions. Rather, what is needed to identify the optimal price is exogenous shifts in costs, or arbitrary changes in prices (e.g. as generated by a randomized field experiment). ${ }^{26}$

\footnotetext{
${ }^{26}$ See Hoch et al. (1995) for one example of an attempt to estimate price elasticities of demand for a grocery retailer. The same endogeneity bedevils firm choices of the optimal quantity of advertising expenditure, although the opportunities for low-cost experimentation are likely to be greater on this
} 
The findings of this paper suggest that the absence of feedback (along with the inherent difficulty of the problem) makes it possible to sustain long run deviations from optimal pricing by an otherwise sophisticated decision maker.

dimension, at least when a good is sold in multiple markets and media is market specific (see, for example, Ackoff and Emshoff 1975). 


\section{Data Appendix}

The data used in this paper were provided by the founder of the company. Recent years of data were in Excel spreadsheets; earlier years were in hard copy that were scanned or hand entered.

The primary use of the data was for accounting purposes. A number of steps were taken to clean the data for the analysis in this paper. I exclude all clients in which the company prepays, as opposed to the goods being purchased on the honor system. In a handful of cases, there were small variations in company names over time, although it is clear from the data that these represent the same customers and were treated accordingly. When multiple deliveries were made to different floors of the same company, or to the same floor on different days of the week, these were treated as different customers. I excluded all observations in which the quantity delivered of bagels and donuts are both reported as zero, and all observations in which no quantities eaten were reported in the data. On the advice of the company, I excluded cases in which the revenues received were either less than 25 percent of the number that would have been expected based on the posted prices and the number of products consumed, or more than 150 percent of the expected number; the company says that occasionally they lump together the results of multiple deliveries to a client in their bookkeeping. In a small number of cases, the accounting identity regarding costs, revenues, and profits for a delivery did not hold. These observations were dropped, as were duplicate entries corresponding to the same delivery. I also dropped a small number of cases in which the quantities delivered were far higher than in the preceding and following weeks.

The data I was given has information on the total cost associated with the products delivered to a given client on a particular day, but is not specifically broken out between bagels, cream cheese, and donuts. To estimate marginal cost of a bagel (including cream cheese), I limit the sample to customers who only receive bagels (no donuts) and run regressions by calendar year with the total product cost on the left-hand side and the number of bagels delivered on the right-hand side, with no constant. Because the wholesale cost of the product fluctuates within a calendar year and the ratio of bagels to cream cheese varies by customer, the fit of the regression is less than one. In all but two years of the sample, the R-squared of this regression is above .99. I then estimate the marginal cost of a donut by subtracting off the fitted value of the costs of the bagels delivered and running a parallel regression on donuts. The R-squared of this regression is above .97 in all but two years. The resulting data set includes just over 80,000 valid customer deliveries. 


\section{$\underline{\text { References }}$}

Ackerberg, Daniel, Lanier Benkard, Steven Berry, and Ariel Pakes, 2005, "Econometric Tools for Analyzing Market Outcomes," Forthcoming, Handbook of Econometrics.

Ackoff, R., and Emshoff, K. Advertising research at Anheuser-Busch, Inc. (1963-1968). Sloan Management Review, 1975, 16(2), 1-15.

Becker, Gary, 1991, “A Note on Restaurant Pricing and Other Examples of Social Influences on Price," The Journal of Political Economy, Vol. 99, No. 5. (Oct., 1991), pp. 1109-1116.

Berry, Steven, James Levinsohn, and Ariel Pakes, 1995, “Automobile Prices in Market Equilibrium,” Econometrica, Vol. 63, No. 4. (Jul., 1995), pp. 841-890.

Bils, Mark, and Pete Klenow, 2004, "Some Evidence on the Importance of Sticky Prices," Journal of Political Economy, Vol. 112, No. 5, pp. 947-985,

Bresnahan, Timothy, 1987, "Competition and Collusion in the American Automobile Industry: The 1955 Price War," Journal of Industrial Economics, vol. 35(4), pages 457-82.

Bresnahan, Tim and Peter Reiss, 1991. "Entry and Competition in Concentrated Markets," Journal of Political Economy, vol. 99(5), pages 977-1009.

Cecchetti, Stephen, 1986, "The Frequency of Price Adjustment: A Study of the Newsstand Prices of Magazines," Journal of Econometrics 31 (April): 255-74.

Evans, James and William Lindsay, 1998, The Management and Control of Quality, South-Western Educational Publishing, $4^{\text {th }}$ edition.

Feldman, Paul, 1971, "Efficiency, Distribution, and the Role of Government in a Market Economy," Journal of Political Economy. Vol. 79, No. 3 (May, 1971), pp. 508526.

Feldman, Paul and John Jondrow, "Congressional Elections and Local Federal Spending," American Journal of Political Science, Vol. 28, No. 1. (Feb., 1984), pp. 147-164.

Genesove, David, and Wallace P. Mullin, 1998, “Testing Static Oligopoly Models: Conduct and Cost in the Sugar Industry, 1890-1914, The RAND Journal of Economics,(Summer 1998) 29: 355-377 
Hoch, Stephen, Byung-Do Kim, Alan Montgomery, and Peter Rossi, 1995, "Determinants of Store-Level Price Elasticity," Journal of Marketing Research, Vol. 32, No. 1. (Feb., 1995), pp. 17-29.

Hortacsu, Ali and Steven Puller, 2005, "Testing Strategic Models of Bidding in Deregulated Electricity Markets: A Case Study of ERCOT," University of Chicago Working Paper.

Kashyap, Anil, 1995, “Sticky Prices: New Evidence from Retail Catalogs," Quarterly Journal of Economics, 110 (February): 245-74.

Levitt, Steven, 2006, "White-Collar Crime Writ Small: A Case Study of Bagels, Donuts, and the Honor System," Forthcoming, AEA Papers and Proceedings.

Levitt, Steven, and Stephen Dubner, 2005, Freakonomics: A Rogue Economist Explores the Hidden Side of Everything,_New York: William Morrow.

Pakes, Ariel, 1986, "Patents as Options: Some Estimates of the Value of Holding European Patent Stocks," Econometrica, Vol. 54, No. 4. (Jul., 1986), pp. 755-784.

Rosse, James N., 1970, "Estimating Cost Function Parameters Without Using Cost Data: Illustrated Methodology," Econometrica .Vol. 38, No. 2 (Mar., 1970), pp. 256275 Rosse, 1970

Silver, E. A., D. F. Pyke, and R. Peterson, 1998, Inventory Management and Production Planning and Scheduling, New York: John Wiley \& Sons.

Wolfram, Catherine, 1999, "Measuring Duopoly Power in the British Electricity Spot Market," The American Economic Review , Vol. 89, No. 4 (Sep., 1999), pp. 805826 
Figure 1: Aggregate Quantities Delivered and Eaten

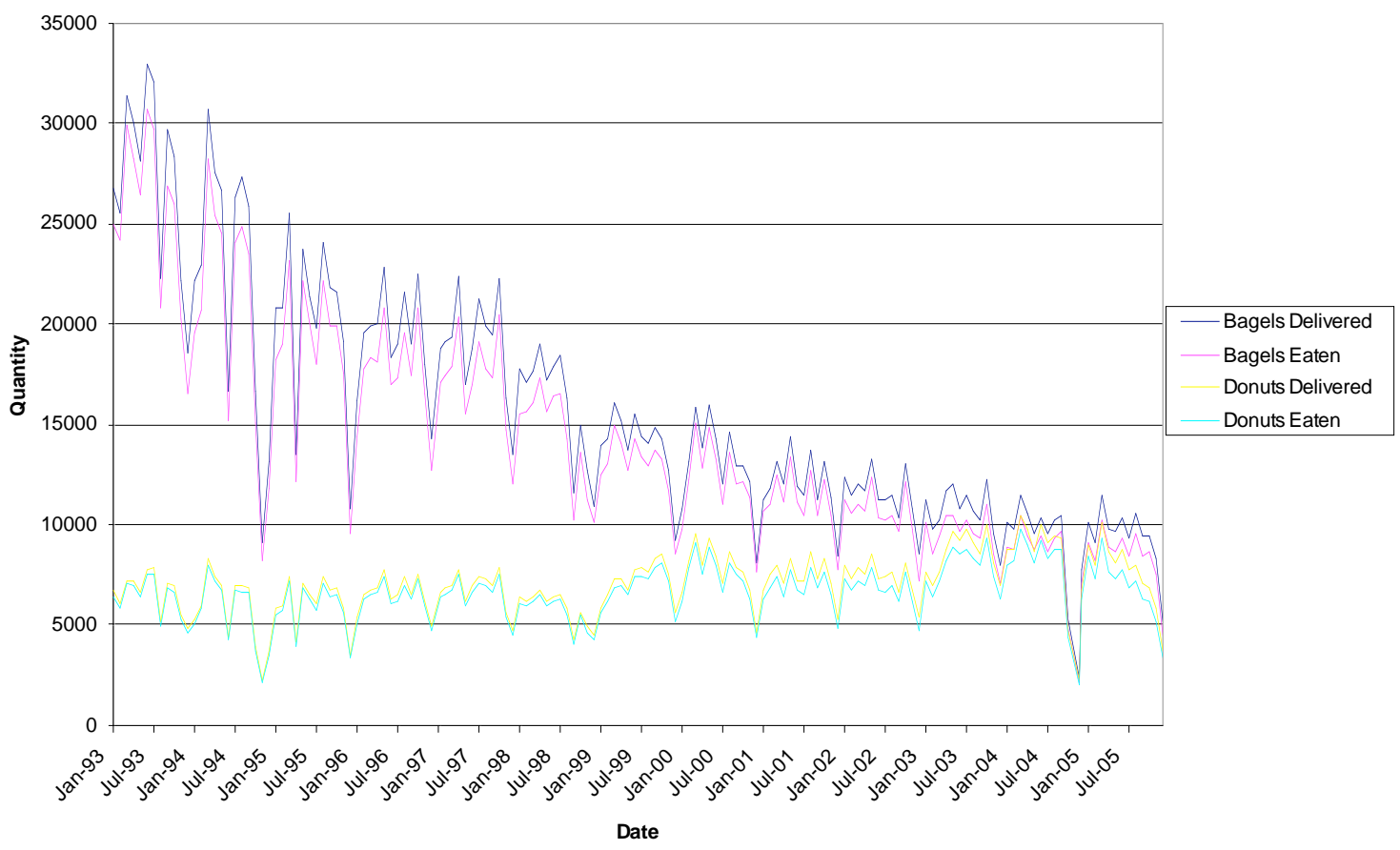


Table 1: Summary Statistics

\begin{tabular}{|c|c|c|c|}
\hline Variable & Mean & Standard Deviation & $\begin{array}{l}\text { Within-customer } \\
\text { standard deviation }\end{array}$ \\
\hline Number of bagels delivered & 30.243 & 24.721 & 13.769 \\
\hline Number of bagels eaten & 27.638 & 23.981 & 13.413 \\
\hline Number of donuts delivered & 13.624 & 13.369 & 6.293 \\
\hline Number of donuts eaten & 12.808 & 13.025 & 6.176 \\
\hline Posted price of bagel (nominal \$) & 0.825 & 0.106 & 0.070 \\
\hline Posted price of donuts (nominal \$) & 0.506 & 0.023 & 0.020 \\
\hline Payment rate & 0.893 & 0.118 & 0.108 \\
\hline Marginal cost of bagel (nominal $\$$ ) & 0.271 & 0.059 & 0.035 \\
\hline Marginal cost of donut (nominal \$) & 0.219 & 0.017 & 0.015 \\
\hline Year & 1998.823 & 3.709 & 2.163 \\
\hline
\end{tabular}

Notes: The unit of observation is a delivery. Data reflect 80,731 deliveries over the period 1993-2005.

The payment rate is the fraction of the posted price that the company actually receives on the honor system. The marginal cost is the wholesale price of a bagel or donut. The final column presents the standard deviation of the variables within a particular customer over time. See the data appendix for a more detailed description of the data set and its construction. 
Table 2: Estimated Profitability of the Last Bagel Delivered when Bagels are the Only Product Delivered

\begin{tabular}{|c|c|c|c|c|c|c|c|}
\hline & (1) & (2) & (3) & (4) & (5) & (6) & (7) \\
\hline Year & $\begin{array}{c}\text { Average } \\
\text { posted price } \\
\text { of bagel }\end{array}$ & $\begin{array}{l}\text { Marginal } \\
\text { cost of } \\
\text { bagel }\end{array}$ & $\begin{array}{l}\text { Payment } \\
\text { rate }\end{array}$ & $\begin{array}{c}\operatorname{Pr} \text { (all bagels } \\
\text { eaten) }\end{array}$ & $\begin{array}{l}\text { Expected profit } \\
\text { from next to last } \\
\text { bagel delivered }\end{array}$ & $\begin{array}{l}\text { Expected profit } \\
\text { from last bagel } \\
\text { delivered }\end{array}$ & $\begin{array}{l}\text { Expected profit if } \\
\text { one extra bagel } \\
\text { had been delivered }\end{array}$ \\
\hline 1993 & 0.646 & 0.210 & 0.924 & 0.366 & 0.083 & 0.009 & -0.047 \\
\hline 1994 & 0.750 & 0.203 & 0.914 & 0.315 & 0.096 & 0.013 & -0.047 \\
\hline 1995 & 0.750 & 0.202 & 0.909 & 0.348 & 0.116 & 0.035 & -0.025 \\
\hline 1996 & 0.750 & 0.211 & 0.907 & 0.300 & 0.089 & -0.007 & -0.073 \\
\hline 1997 & 0.750 & 0.221 & 0.900 & 0.326 & 0.079 & -0.001 & -0.059 \\
\hline 1998 & 0.785 & 0.253 & 0.896 & 0.339 & 0.061 & -0.015 & -0.073 \\
\hline 1999 & 0.850 & 0.282 & 0.904 & 0.436 & 0.162 & 0.053 & -0.029 \\
\hline 2000 & 0.850 & 0.294 & 0.919 & 0.458 & 0.195 & 0.064 & -0.032 \\
\hline 2001 & 0.850 & 0.307 & 0.900 & 0.477 & 0.177 & 0.059 & -0.031 \\
\hline 2002 & 0.850 & 0.301 & 0.905 & 0.415 & 0.139 & 0.018 & -0.070 \\
\hline 2003 & 0.948 & 0.333 & 0.892 & 0.332 & 0.096 & -0.052 & -0.148 \\
\hline 2004 & 1.000 & 0.369 & 0.881 & 0.369 & 0.112 & -0.044 & -0.149 \\
\hline 2005 & 1.000 & 0.372 & 0.862 & 0.380 & 0.120 & -0.044 & -0.154 \\
\hline $\begin{array}{l}\text { Average ov } \\
\text { all years }\end{array}$ & 0.780 & 0.244 & 0.906 & 0.360 & 0.105 & 0.011 & -0.058 \\
\hline
\end{tabular}

Note: Each row corresponds to average values for all deliveries in the listed calendar year for customers receiving bagels only.

Columns (1) to (4) are observed in the data. Columns (5) to (7) are estimates using equation (1) of the paper to compute the

expected profit from the next to last bagel delivered, the last bagel delivered, and if one extra bagel were delivered.

Column (7) is calculated under the assumption that the likelihood that the

$N+1$ bagel is eaten conditional on the

eaten is equal to the probability the

$N$ th was eaten conditional on the

$N-1$ bagel was eaten. 
Table 3: Estimates of the Cannibalization Rate Across Products

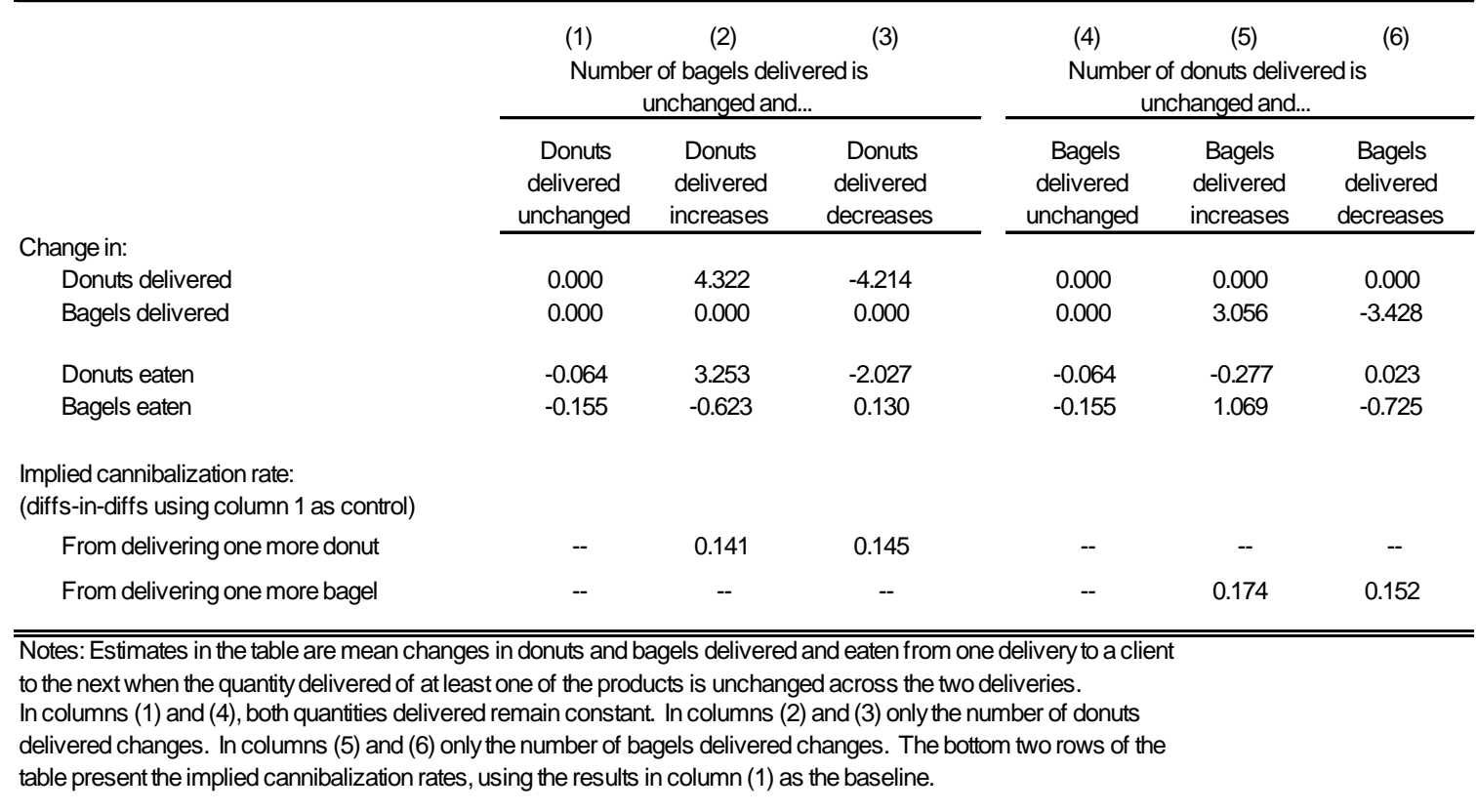


Table 4: Estimated Profitability of the Last Bagel Eaten (when both products delivered)

\begin{tabular}{|c|c|c|c|c|c|c|c|c|}
\hline & (1) & (2) & (3) & (4) & (5) & (6) & (7) & (8) \\
\hline Year & $\begin{array}{c}\text { Average } \\
\text { posted price of } \\
\text { bagel }\end{array}$ & $\begin{array}{c}\text { Marginal cost of } \\
\text { bagel }\end{array}$ & $\begin{array}{l}\text { Payment } \\
\text { rate }\end{array}$ & $\begin{array}{l}\text { Probability all } \\
\text { bagels eaten: }\end{array}$ & $\begin{array}{c}\text { Probability all } \\
\text { bagels eaten and } \\
\text { excess of donuts }\end{array}$ & $\begin{array}{l}\text { Expected profit from } \\
\text { next to last bagel } \\
\text { delivered }\end{array}$ & $\begin{array}{l}\text { Expected profit } \\
\text { from last bagel } \\
\text { delivered }\end{array}$ & $\begin{array}{l}\text { Expected profit if } \\
\text { one extra bagel } \\
\text { had been delivered }\end{array}$ \\
\hline 1993 & 0.646 & 0.210 & 0.907 & 0.364 & 0.054 & 0.055 & 0.0002 & -0.045 \\
\hline 1994 & 0.750 & 0.203 & 0.893 & 0.328 & 0.051 & 0.079 & 0.0127 & -0.040 \\
\hline 1995 & 0.750 & 0.202 & 0.888 & 0.355 & 0.049 & 0.105 & 0.0304 & -0.027 \\
\hline 1996 & 0.750 & 0.211 & 0.884 & 0.353 & 0.055 & 0.098 & 0.0190 & -0.041 \\
\hline 1997 & 0.750 & 0.221 & 0.883 & 0.355 & 0.057 & 0.079 & 0.0101 & -0.045 \\
\hline 1998 & 0.785 & 0.253 & 0.874 & 0.360 & 0.069 & 0.066 & -0.0108 & -0.071 \\
\hline 1999 & 0.850 & 0.282 & 0.881 & 0.433 & 0.113 & 0.136 & 0.0339 & -0.046 \\
\hline 2000 & 0.850 & 0.294 & 0.880 & 0.489 & 0.127 & 0.174 & 0.0631 & -0.022 \\
\hline 2001 & 0.850 & 0.307 & 0.878 & 0.448 & 0.151 & 0.135 & 0.0170 & -0.070 \\
\hline 2002 & 0.850 & 0.301 & 0.899 & 0.413 & 0.132 & 0.118 & 0.0044 & -0.079 \\
\hline 2003 & 0.948 & 0.333 & 0.893 & 0.370 & 0.106 & 0.100 & -0.0252 & -0.115 \\
\hline 2004 & 1.000 & 0.369 & 0.892 & 0.415 & 0.130 & 0.143 & -0.0080 & -0.115 \\
\hline 2005 & 1.000 & 0.372 & 0.901 & 0.408 & 0.161 & 0.135 & -0.0182 & -0.126 \\
\hline $\begin{array}{l}\text { Average ov } \\
\text { all years }\end{array}$ & 0.780 & 0.244 & 0.889 & 0.394 & 0.100 & 0.108 & 0.008 & -0.068 \\
\hline
\end{tabular}

Note: Each row corresponds to average values for all deliveries in the listed calendar year for customers receiving both bagels and donuts.

Columns (1) to (5) are observed in the data. Columns (6) to (8) are estimates using equation (2) of the paper to compute the

expected profit from the next to last bagel delivered, the last bagel delivered, and if one extra bagel were delivered. These

estimates use the cannibalization estimates obtained in Table 3. 
Table 5: Estimated Profitability of the Last Donut Eaten (when both products delivered)

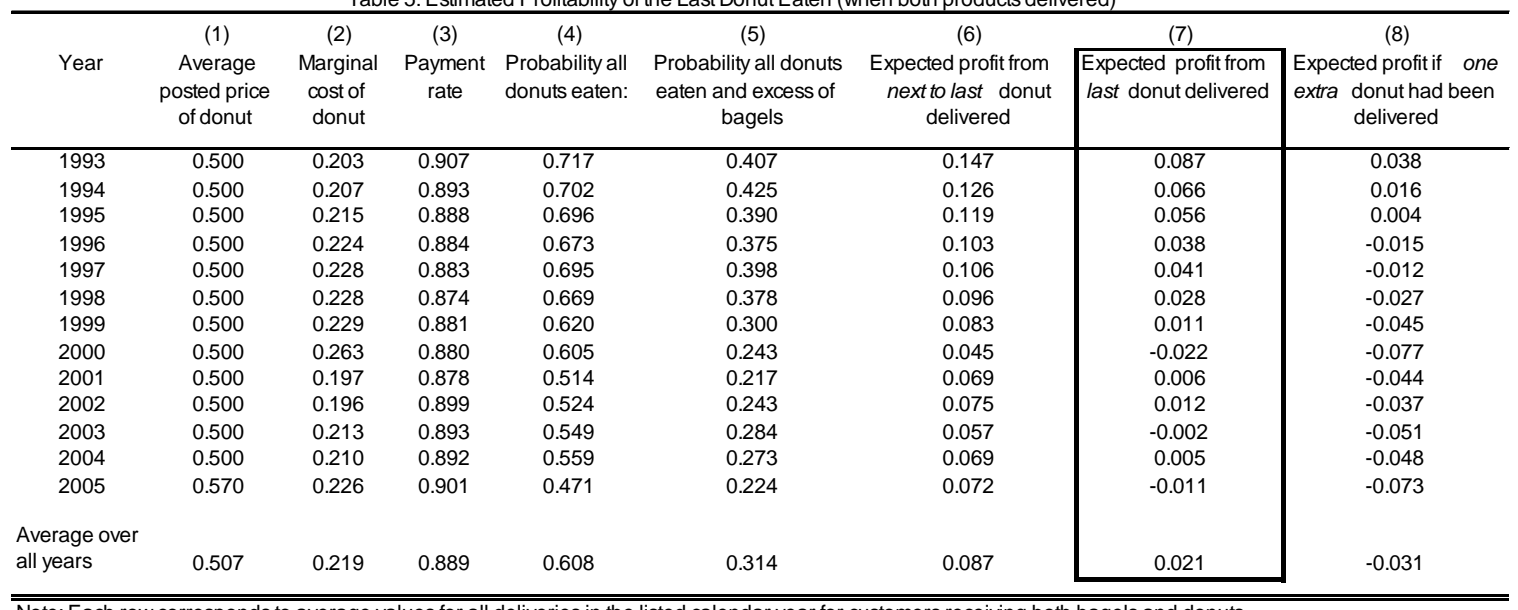

Note: Each row corresponds to average values for all deliveries in the listed calendar year for customers receiving both bagels and donuts.

Columns (1) to (5) are observed in the data. Columns (6) to (8) are estimates using equation (3) of the paper to compute the

expected profit from the next to last donut delivered, the last donut delivered, and if one extra donut were delivered. These

estimates use the cannibalization estimates obtained in Table 3. 
Table 6: Predicting Stock-outs from Observable Characteristics

\begin{tabular}{|c|c|c|c|c|}
\hline \multicolumn{5}{|c|}{ Can Regression Improve on the Company's Choices? } \\
\hline Bagels & \multicolumn{4}{|c|}{$\begin{array}{l}\text { Distribution of uneaten bagels, by regression prediction of degree of shortfall or } \\
\text { excess of bagels delivered }\end{array}$} \\
\hline & $(1)$ & $(2)$ & (3) & (4) \\
\hline $\begin{array}{l}\text { Observed number of } \\
\text { bagels left }\end{array}$ & $\begin{array}{c}10 \% \text { of observations } \\
\text { with greatest } \\
\text { predicted bagel } \\
\text { shortfall }\end{array}$ & $\begin{array}{l}50 \% \text { of } \\
\text { observations with } \\
\text { greatest predicted } \\
\text { bagel shortfall }\end{array}$ & $\begin{array}{l}50 \% \text { of } \\
\text { observations with } \\
\text { greatest predicted } \\
\text { bagel surplus }\end{array}$ & $\begin{array}{c}10 \% \text { of } \\
\text { observations with } \\
\text { greatest predicted } \\
\text { bagel surplus }\end{array}$ \\
\hline Zero & 0.527 & 0.468 & 0.334 & 0.256 \\
\hline One & 0.127 & 0.140 & 0.141 & 0.124 \\
\hline Two & 0.094 & 0.107 & 0.123 & 0.115 \\
\hline Three & 0.071 & 0.083 & 0.101 & 0.104 \\
\hline Four & 0.047 & 0.060 & 0.080 & 0.086 \\
\hline Five or more & 0.135 & 0.142 & 0.220 & 0.315 \\
\hline \multicolumn{5}{|l|}{ Expected profit on: } \\
\hline next to last bagel & 0.201 & 0.174 & 0.080 & 0.009 \\
\hline last bagel & 0.104 & 0.065 & -0.031 & -0.090 \\
\hline extra bagel & 0.023 & -0.020 & -0.109 & -0.155 \\
\hline
\end{tabular}

\begin{tabular}{|c|c|c|c|c|}
\hline \multirow{2}{*}{$\begin{array}{l}\text { Donuts } \\
\\
\text { Observed number of } \\
\text { donuts left }\end{array}$} & \multicolumn{4}{|c|}{$\begin{array}{l}\text { Distribution of uneaten donuts, by regression prediction of degree of shortfall or } \\
\text { excess of donuts delivered }\end{array}$} \\
\hline & $\begin{array}{c}10 \% \text { of observations } \\
\text { with greatest } \\
\text { predicted donut } \\
\text { shortfall }\end{array}$ & $\begin{array}{l}50 \% \text { of } \\
\text { observations with } \\
\text { greatest predicted } \\
\text { donut shortfall }\end{array}$ & $\begin{array}{l}50 \% \text { of } \\
\text { observations with } \\
\text { greatest predicted } \\
\text { donut surplus }\end{array}$ & $\begin{array}{l}10 \% \text { of } \\
\text { observations with } \\
\text { greatest predicted } \\
\text { donut surplus }\end{array}$ \\
\hline Zero & 0.752 & 0.693 & 0.502 & 0.393 \\
\hline One & 0.115 & 0.134 & 0.164 & 0.156 \\
\hline Two & 0.056 & 0.070 & 0.114 & 0.119 \\
\hline Three & 0.036 & 0.041 & 0.077 & 0.093 \\
\hline Four & 0.016 & 0.024 & 0.049 & 0.065 \\
\hline Five or more & 0.025 & 0.037 & 0.094 & 0.173 \\
\hline \multicolumn{5}{|l|}{ Expected profit on: } \\
\hline next to last donut & 0.094 & 0.075 & 0.011 & -0.029 \\
\hline last donut & 0.076 & 0.053 & -0.018 & -0.057 \\
\hline extra donut & 0.057 & 0.029 & -0.049 & -0.092 \\
\hline \multicolumn{5}{|c|}{$\begin{array}{l}\text { Notes: The results in the table report the number of bagels (top panel) and donuts (bottom panel) } \\
\text { that go uneaten depending on the predictions of a probit model designed to improve on the quantity } \\
\text { choices of the company. The probit model uses only information observable to the company ex ante } \\
\text { and is estimated on the prior two calendar years of data and extrapolated out of sample. }\end{array}$} \\
\hline \multicolumn{5}{|c|}{$\begin{array}{l}\text { Deliveries are rank ordered within a year based on the predicted likelihood of a stockout. Column (1) } \\
\text { reports actual bagels uneaten in the } 10 \% \text { of deliveries predicted to be most likely to stock out. }\end{array}$} \\
\hline \multicolumn{5}{|c|}{$\begin{array}{l}\text { Columns (2) and (3) are outcomes for deliveries above and below the median predicted stock out. } \\
\text { Column (4) corresponds to the } 10 \text { percent of deliveries predicted to be least likely to stock out. } \\
\text { For each type of good in each column, the estimated profitability of the next to last, last, and one }\end{array}$} \\
\hline
\end{tabular}


Table 7: Changes in Profits and Revenue in Response to Price Changes

\begin{tabular}{|c|c|c|c|c|c|c|c|c|}
\hline \multirow[b]{2}{*}{ Variable } & \multicolumn{2}{|c|}{ August 31, 1993} & \multicolumn{2}{|c|}{ August 4, 1998} & \multicolumn{2}{|c|}{ May 5, 2003} & \multicolumn{2}{|c|}{ March 28, 2005} \\
\hline & Before & After & Before & After & Before & After & Before & After \\
\hline$\overline{\text { Price of bagel }}$ & 0.60 & 0.75 & 0.75 & 0.85 & 0.85 & 1.00 & 1.00 & 1.00 \\
\hline Price of donut & 0.50 & 0.50 & 0.50 & 0.50 & 0.50 & 0.50 & 0.50 & 0.60 \\
\hline Marginal cost of bagel & 0.210 & 0.210 & 0.253 & 0.253 & 0.333 & 0.333 & 0.372 & 0.372 \\
\hline Marginal cost of donut & 0.203 & 0.203 & 0.228 & 0.228 & 0.213 & 0.213 & 0.226 & 0.226 \\
\hline Bagels delivered & 51.413 & 49.317 & 30.170 & 29.366 & 23.093 & 22.210 & 19.628 & 19.264 \\
\hline Bagels eaten & 48.230 & 44.283 & 27.091 & 25.541 & 20.750 & 19.360 & 17.697 & 17.465 \\
\hline Donuts delivered & 12.020 & 11.617 & 10.789 & 10.539 & 17.621 & 17.496 & 17.570 & 17.372 \\
\hline Donuts eaten & 11.526 & 11.203 & 10.319 & 9.885 & 16.417 & 16.033 & 16.427 & 15.457 \\
\hline Payment rate & 0.914 & 0.888 & 0.890 & 0.889 & 0.913 & 0.885 & 0.904 & 0.889 \\
\hline Total variable cost & 13.298 & 12.765 & 10.097 & 9.838 & 11.430 & 11.109 & 11.274 & 11.093 \\
\hline Total revenue & 31.670 & 34.243 & 22.436 & 23.320 & 23.429 & 23.856 & 23.336 & 23.611 \\
\hline Total profit & 18.369 & 21.464 & 12.338 & 13.482 & 11.999 & 12.746 & 12.063 & 12.517 \\
\hline
\end{tabular}

Note: Results in table are means of the three deliveries immediately preceding and following a price change for all customers who have three such deliveries in the month before and after the price change. All values are in nominal dollars. 
Table 8:Regression Estimates of the Impact of Price Changes on Daily Profits

\begin{tabular}{|c|c|c|c|}
\hline & \multicolumn{3}{|c|}{ Total Profits } \\
\hline & (1) & (2) & (3) \\
\hline $\begin{array}{l}\text { Months in advance of price change: } \\
6 \text { months prior }\end{array}$ & ---- & ---- & $\begin{array}{l}-21.194 \\
(17.400)\end{array}$ \\
\hline 5 months prior & ---- & ---- & $\begin{array}{l}-23.803 \\
(18.154)\end{array}$ \\
\hline 4 months prior & ---- & ---- & $\begin{array}{r}-9.388 \\
(16.363)\end{array}$ \\
\hline 3 months prior & ---- & $\begin{array}{c}-4.033 \\
(16.192)\end{array}$ & $\begin{array}{c}1.533 \\
(16.965)\end{array}$ \\
\hline 2 months prior & ---- & $\begin{array}{c}-5.713 \\
(16.380)\end{array}$ & $\begin{array}{c}-0.277 \\
(17.268)\end{array}$ \\
\hline 1 month prior & $\begin{array}{l}-19.713 \\
(16.178)\end{array}$ & $\begin{array}{l}-11.772 \\
(16.436)\end{array}$ & $\begin{array}{c}-5.958 \\
(17.421)\end{array}$ \\
\hline Months following a price change: & & & \\
\hline 1 month after & $\begin{array}{l}45.260 \\
(15.471)\end{array}$ & $\begin{array}{l}53.410 \\
(15.695)\end{array}$ & $\begin{array}{r}59.539 \\
(16.697)\end{array}$ \\
\hline 2 months after & ---- & $\begin{array}{c}59.082 \\
(16.934)\end{array}$ & $\begin{array}{r}65.200 \\
(17.746)\end{array}$ \\
\hline 3 months after & ---- & $\begin{array}{c}60.331 \\
(16.512)\end{array}$ & $\begin{array}{r}67.575 \\
(17.333)\end{array}$ \\
\hline 4 months after & ---- & ---- & $\begin{array}{r}41.351 \\
(16.557)\end{array}$ \\
\hline 5 months after & ---- & ---- & $\begin{array}{r}27.795 \\
(16.635)\end{array}$ \\
\hline 6 months after & ---- & ---- & $\begin{array}{c}23.975 \\
(15.855)\end{array}$ \\
\hline Year dummies included? & Yes & Yes & Yes \\
\hline Month dummies included? & Yes & Yes & Yes \\
\hline Day of the week dummies included? & Yes & Yes & Yes \\
\hline $\mathrm{R}^{\wedge} 2$ & 0.713 & 0.716 & 0.718 \\
\hline F-test:Months prior jointly equal to zero? & 0.223 & 0.897 & 0.773 \\
\hline F-test:Months after jointly equal to zero? & 0.004 & 0.000 & 0.000 \\
\hline F-test:Months after jointly different from months prior & 0.001 & 0.000 & 0.000 \\
\hline $\begin{array}{l}\text { Notes: The results in the table are regression coefficie } \\
\text { regression with one observation per day. The depen } \\
\text { day. Year, month, and day of the week dummies are } \\
\text { Standard errors in parentheses. The bottom three ro } \\
\text { from tests that the coefficients on the month(s) immedi } \\
\text { price changes are jointly statistically significant differe } \\
\text { observations included in the regression is } 2,262 \text {. }\end{array}$ & $\begin{array}{l}\text { a time-se } \\
\text { riable is to } \\
\text { d in all spe } \\
\text { e table rep } \\
\text { receding o } \\
\text { zero. The }\end{array}$ & $\begin{array}{l}\text { s } \\
\text { orofit for th } \\
\text { cations. } \\
\text { p-values } \\
\text { llowing the } \\
\text { mber of }\end{array}$ & \\
\hline
\end{tabular}

